\title{
SOIL-STRUCTURE INTERACTION DURING THE SAN FERNANDO EARTHQUAKE
}

\author{
By Charles B. Crouse and Paul C. Jennings
}

\begin{abstract}
Accelerograms obtained at two sites during the San Fernando earthquake of 1971 were analyzed to investigate the role of soil-structure interaction, using techniques developed by Bielak and others. Analysis of the data from the site of the Hollywood Storage Building, for which data from the Arvin-Tehachapi earthquake of 1952 are also available, showed evidence of soil-structure interaction in the way the transfer functions between parking lot and basement motion decayed with increasing frequency in the two lateral directions. It is concluded also that interaction probably had a small effect on the response near the EW fundamental frequency during the San Fernando earthquake. Although theoretical and experimentally determined transfer functions are broadly similar, they do not agree in detail. The lack of good agreement for reasonable choices of the parameters of the theoretical model indicates a need for some modifications of the theory or its application, and a need for more measurements at the site.

A similar analysis showed no clear evidence of soil-structure interaction for the Millikan Library and Athanaeum buildings on the campus of the California Institute of Technology. If soil-structure interaction caused the major differences measured in the base motions of these two buildings, it is of a more complex form than that considered by present theories.
\end{abstract}

\section{INTRODUCTION}

Theories of soil-structure interaction have been developed over the years to predict how the flexibility of the soil beneath a structure can modify its dynamic response. Prior to the San Fernando earthquake, however, it was difficult to evaluate the theoretical results because of the lack of experimental data: only at the Hollywood Storage Building (Housner, 1957) had both free-field and structural response been measured. In the present study, theoretical techniques developed by Bielak and others (Bielak, 1971; Jennings and Bielak, 1973; Parmelee, 1969) are applied to the Hollywood Storage Building in Los Angeles and the closely spaced Millikan Library and Athenaeum buildings on the campus of the California Institute of Technology in Pasadena. The results are compared to measurements made during the San Fernando earthquake. A comparison with the data from the Arvin-Tehachapi earthquake for the Hollywood Storage site (Housner, 1957; Duke et al., 1970) is also included.

The model, shown in Figure la, consists of a linear, viscously damped, $n$-story structure supported on a rigid circular foundation of radius $a$ which is bonded to a linearly elastic, homogeneous, isotropic half-space. In its general form the system has $n+2$ degrees of freedom, translation of each story mass and the base, and rotation of the entire system. Beginning with the system at rest, the equations of motion are usually derived for an excitation consisting of vertically incident planar shear waves, with the assumption of no scattering of waves from the rigid foundation and nearby surfaces. The equations are also applicable, however, for incoming waves at arbitrary angles of incidence provided that the wavelengths are long with respect to the length of the foundation. 
The equations used in the analysis were developed under the assumption that the superstructure possesses classical normal modes. For this case, a model equivalent to that shown in Figure 1a can be constructed (Figure 1b). It consists of $n$ oscillators attached to the rigid circular base, each oscillator defined by a natural frequency, $\omega_{j}$, critical damping ratio, $\eta_{j}$, modal mass, $M_{j}$, modal moment of inertia, $\bar{I}_{j}$, and modal height, $H_{j}$.

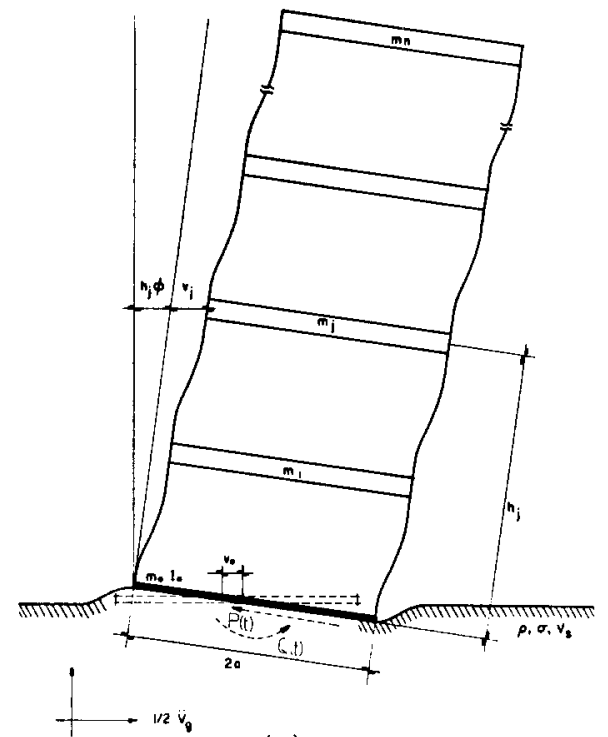

(a)

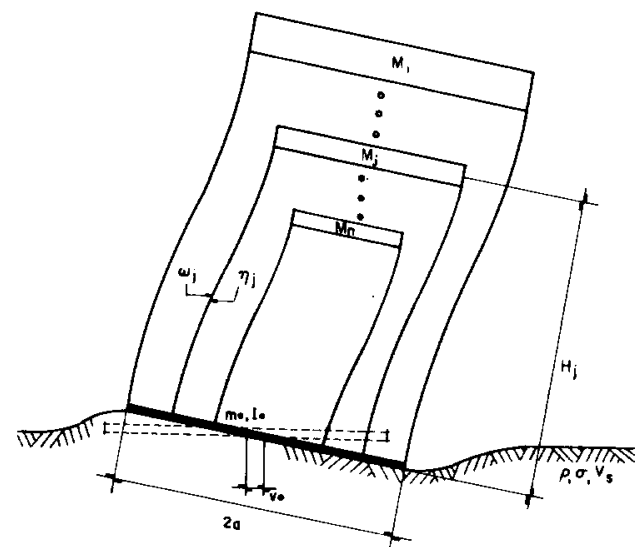

(b)

FIG. 1. Models of Soil-Structure Interaction. (a) Multi-degree-of-freedom structure, (b) equivalent modal representation.

For small displacements the equations of motion for the model shown in Figure la are

$$
\begin{gathered}
M \ddot{v}^{t}+C \dot{v}+K \mathbf{v}=0 \\
\sum_{j=1}^{n} m_{j} \ddot{v}_{j}^{t}+m_{0}\left(\ddot{v}_{0}+\ddot{v}_{g}\right)+P(t)=0 \\
\sum_{j=1}^{n} m_{j} h_{j} \ddot{v}_{j}^{t}+I_{t} \varphi+Q(t)=0 .
\end{gathered}
$$

In these equations: $v_{j}{ }^{t}=$ total horizontal displacement of the $j^{\text {th }}$ mass with respect to a fixed vertical axis, i.e., $v_{j}{ }^{t}=v_{g}+v_{0}+h_{j} \varphi+v_{j} ; I_{t}=$ sum of the centroidal moments of inertia of the $n+1$ masses, and $P(t)$ and $Q(t)$ are the horizontal restoring force and moment, respectively, at the interface between the base mass and the half-space. A complete description of the symbols is given in the Appendix.

A relationship between the generalized interaction forces and generalized base displacements (Arnold et al., 1955; Bycroft, 1956; Kobori et al., 1966) can be written as

$$
\left\{\begin{array}{l}
\overline{\bar{P}(s)} \\
\mu a^{2} \\
\frac{\bar{Q}(s)}{\mu a^{2}}
\end{array}\right\}=\left[\begin{array}{ll}
K_{h h} & K_{h m} \\
K_{m h} & K_{m m}
\end{array}\right]\left\{\begin{array}{c}
\frac{\bar{v}_{0}(s)}{a} \\
\bar{\varphi}(s)
\end{array}\right\} .
$$

In equation (2), $\bar{P}(s)$ and $\bar{Q}(s)$ are Laplace transforms of $P(t)$ and $Q(t)$, respectively, while $K_{h h}, K_{h m}=K_{m h}$, and $K_{m m}$ are the dimensionless, complex impedance functions 
which are functions of frequency and Poisson's ratio. The effects of $K_{h m}$ and $K_{m h}$ are small in comparison with those of the diagonal terms, $K_{h h}$ and $K_{m m}$ (Luco and Westmann, 1971; Veletsos and Wei, 1971; Bielak, 1971) and for the analysis they will be set equal to zero. The functions $K_{h h}$ and $K_{m m}$ were found from solutions to a relaxed mixed boundaryvalue problem, wherein it is assumed that the contact surface between the rigid base and the half-space is frictionless for vertical and rocking motions and is free of normal stresses for horizontal motion. Except for the limiting static case, the dynamic impedance functions have not yet been evaluated for the case of a perfectly bonded rigid plate on an elastic half-space; however, some experimental evidence (Bycroft, 1956; Lysmer and Richart, 1966; Novak, 1973) indicates that the differences in these two cases are small enough not to affect the problem appreciably for low frequencies. Also, theoretical results for an infinite strip (Luco and Westmann, 1972; Oien, 1971) suggest that the effects of the relaxed boundary conditions upon the compliances are not significant for the present problem.

For steady-state harmonic excitation of the rigid base, $K_{k h}$ and $K_{m m}$ can be expressed as (Bycroft, 1956; Gladwell, 1968)

$$
\begin{aligned}
& K_{h h}\left(i a_{0}\right)=k_{h h}\left(a_{0}, \sigma\right)+i a_{0} c_{h h}\left(a_{0}, \sigma\right) \\
& K_{m m}\left(i a_{0}\right)=k_{m m}\left(a_{0}, \sigma\right)+i a_{0} c_{m m}\left(a_{0}, \sigma\right),
\end{aligned}
$$

where $i=\sqrt{ }-1$ and $a_{o}=\omega a / V_{s}$ ( $\omega$ is the frequency of excitation and $V_{s}$ is the velocity of the vertically incident shear waves). $k_{h h}, c_{h h}, k_{m m}$, and $c_{m m}$ are the real functions (Jennings and Bielak, 1973),

$$
\begin{aligned}
k_{h h}\left(a_{o}, \sigma\right) & =\frac{8}{2-\sigma} \beta_{h}\left(a_{o}, \sigma\right) \\
c_{h h}\left(a_{o}, \sigma\right) & =\xi_{h}\left(a_{o}, \sigma\right) k_{h h}\left(a_{o}, \sigma\right) \\
k_{m m}\left(a_{o}, \sigma\right) & =\frac{8}{3(1-\sigma)} \beta_{m}\left(a_{o}, \sigma\right) \\
c_{m m}\left(a_{o}, \sigma\right) & =\xi_{m}\left(a_{o}, \sigma\right) k_{m m}\left(a_{o}, \sigma\right) .
\end{aligned}
$$

The functions $\beta_{h}, \beta_{m}, \xi_{h}, \xi_{m}$, shown in Figure 2, were evaluated from the numerical results presented by Luco and Westmann (1971), for values of the frequency parameter, $a_{o}$, up to 6 and for a Poisson's ratio, $\sigma$, of $1 / 4$. The functions are not affected appreciably by changes in $\sigma$ in the range $0 \leqq \sigma \leqq 1 / 3$.

Since the superstructure is assumed to possess classical normal modes, equations (1) can be solved for the base displacement in terms of the free-field acceleration and transfer functions involving the modal quantities, $M_{j}, H_{j}, \bar{I}_{j}$, the natural frequencies, $\omega_{j}$, and the modal damping ratios, $\eta_{j}$, of the superstructure. The result, expressed in terms of Laplace transformation, is (Bielak, 1971)

$$
\bar{y}_{o}(s)=\overline{\vec{v}}_{g}(s) \frac{\Delta_{o}(s)}{\Delta(s)}+\bar{v}_{g}(s)
$$

where $y_{o}=v_{o}+v_{g}$ is the total lateral displacement of the base mass. Taking the base mass to be initially at rest, equation (5) becomes (replacing the transform variable $s$ by $i \omega$ )

$$
\frac{\bar{y}_{o}(\omega)}{\overline{\bar{v}}_{g}(\omega)}=\frac{-\omega^{2} \Delta_{o}+\Delta}{\Delta} .
$$


Expressions for $\Delta_{o}$ and $\Delta$ are given in the Appendix. Equation (6) was used for comparisons with the earthquake data.

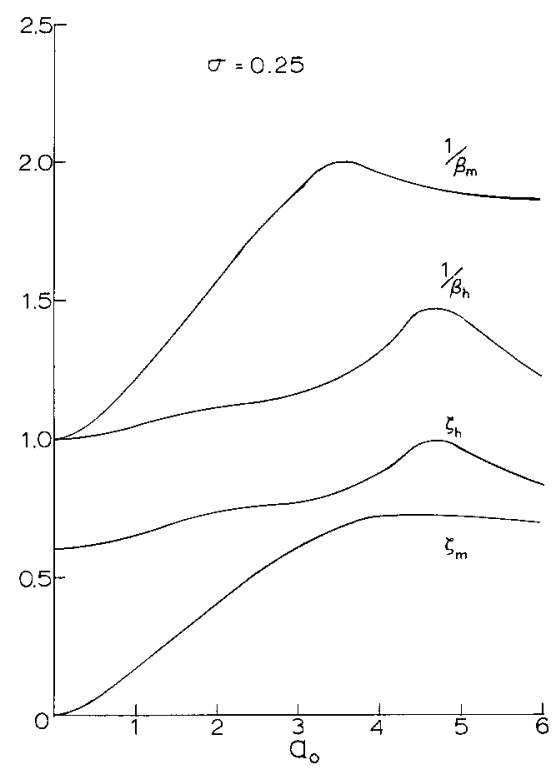

FIG. 2. Values of $1 / \beta$ and $\xi$ for Poisson's ratio, $\sigma$, of $1 / 4$.

\section{RESULTS}

Hollywood Storage Building. The Hollywood Storage Building is located near the corner of Santa Monica Boulevard and Highland Avenue in Los Angeles, and was about 18 miles south of the center of energy release in the San Fernando earthquake (Jennings, 1971). The building is a 14-story, reinforced concrete frame structure, $150 \mathrm{ft}$ tall, with a basement $9 \mathrm{ft}$ beneath the ground story. The foundation consists of concrete piles 10 to $30 \mathrm{ft}$ long, spaced every $17 \mathrm{ft}$ in each direction. Lateral dimensions of the building are $51 \mathrm{ft}(\mathrm{NS})$ by $217 \mathrm{ft}(\mathrm{EW})$. A soil boring to a depth of $100 \mathrm{ft}$ revealed a soft, sandy clay mixture with a weight density varying from $100 \mathrm{lb} / \mathrm{ft}^{3}$ at the surface to roughly $130 \mathrm{lb} / \mathrm{ft}^{3}$ (Duke and Leeds, 1962). Figure 3 shows the building and a small shed $112 \mathrm{ft}$ directly west of the southwest corner of the main building, which contained a Standard strongmotion accelerograph. The accelerograph in the basement of the main building was also a Standard.

The major portions of the horizontal components of the accelerograms obtained during the San Fernando earthquake from the basement and shed are shown in Figure 4. In the parking lot, the larger peaks of the accelerograms are generally $0.05 \mathrm{~g}$ to $0.1 \mathrm{~g}$ greater than corresponding peaks in the basement records. In the analysis of the Hollywood Storage Building, the accelerograms from the shed were assumed representative of the free-field motion.

The Fourier Amplitude Spectra (FAS) of selected 20.48-sec portions of the accelerograms were calculated by a Fast Fourier Transform technique. Comparisons of the FAS (Figure 5) show close agreement between the basement and free-field motions for frequencies up to $4 \mathrm{~Hz}$ in both lateral components. For frequencies greater than $4 \mathrm{~Hz}$, the free-field FAS are significantly larger than the corresponding basement FAS. The FAS in Figure 5 have been smoothed once with a Hanning spectral window weighted 

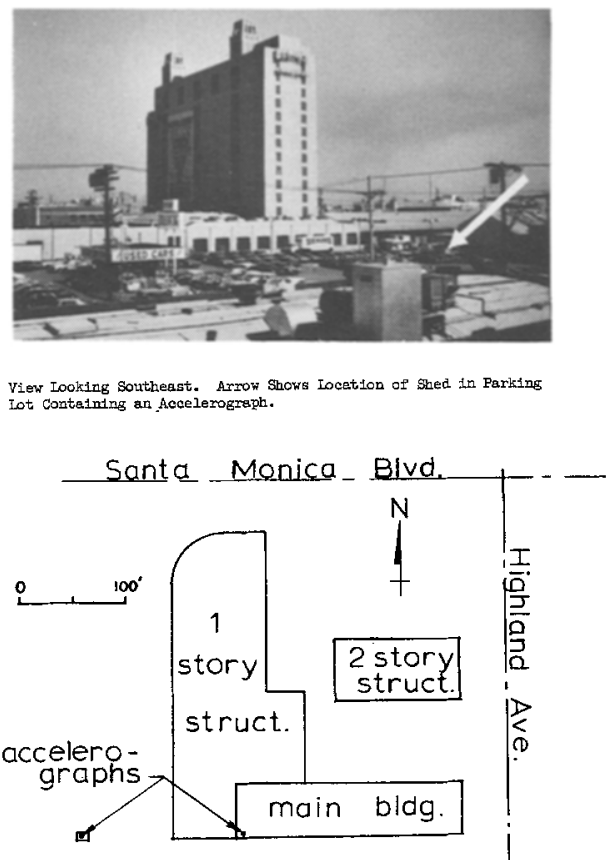

Fig. 3. Hollywood Storage Site in Los Angeles.

$1 / 4,1 / 2$ and $1 / 4$. The frequency spacing of the calculated ordinates is $0.05 \mathrm{~Hz}$. A transfer function between the basement and free-field motions in corresponding directions was achieved by dividing the once-smoothed basement FAS by the once-smoothed free-field FAS and smoothing this ratio 10 times. The additional smoothing of the transfer function was done to emphasize the overall trend and to eliminate large fluctuations. Data reduction for the Arvin-Tehachapi accelerograms was identical to the process just described for the San Fernando data.

The calculation of the necessary parameters for the theoretical model was based on data collected by Duke (Duke and Leeds, 1962; Duke et al., 1970). A $P$-wave velocity of $2400 \mathrm{ft} / \mathrm{sec}$ was measured at the site at depths from 9 to $60 \mathrm{ft}$. Experiments measuring both the shear-wave and $P$-wave velocities at other sites indicate that the shear-wave velocity is on the average half the $P$-wave velocity (Duke and Leeds, 1962). This corresponds to the theoretical result for $\sigma=1 / 3$. Also, there is experimental evidence that the shear modulus of soil is a nonlinear function of the shearing strain. Typical shearing strains produced by earthquakes can reduce the shear modulus to approximately onehalf the value determined by tests at low strain levels (Seed and Idriss, 1970). This indicates that the shear velocity would be reduced by a factor of $1 / \sqrt{ } 2$. Thus, an estimate for the shear-wave velocity during strong motion at the site would be about $800 \mathrm{ft} / \mathrm{sec}$. The average weight density, $\rho$, from the soil borings is $115 \mathrm{lb} / \mathrm{ft}^{3}$. The equivalent base radius, $a$, for a circle whose area is equal to the cross-sectional area of the main building is $59.4 \mathrm{ft}$. The story masses and equivalent interstory stiffnesses of the building were taken from Duke et al. (1970). The natural frequencies and mode shapes of the superstructure were found by solving the eigenvalue problem for a 14-degree-of-freedom, linear, springmass system. The first four calculated frequencies in the NS direction were 1.05, 2.74, 4.30 and $5.84 \mathrm{~Hz}$. Vibration tests before the San Fernando earthquake (Carder, 1964) gave NS resonant frequencies at $0.83,2.7$ and $4.5 \mathrm{~Hz}$. The EW natural frequencies, calculated from the eigenvalue problem, were within 5 per cent of 2,6 and $10 \mathrm{~Hz}$, the natural 


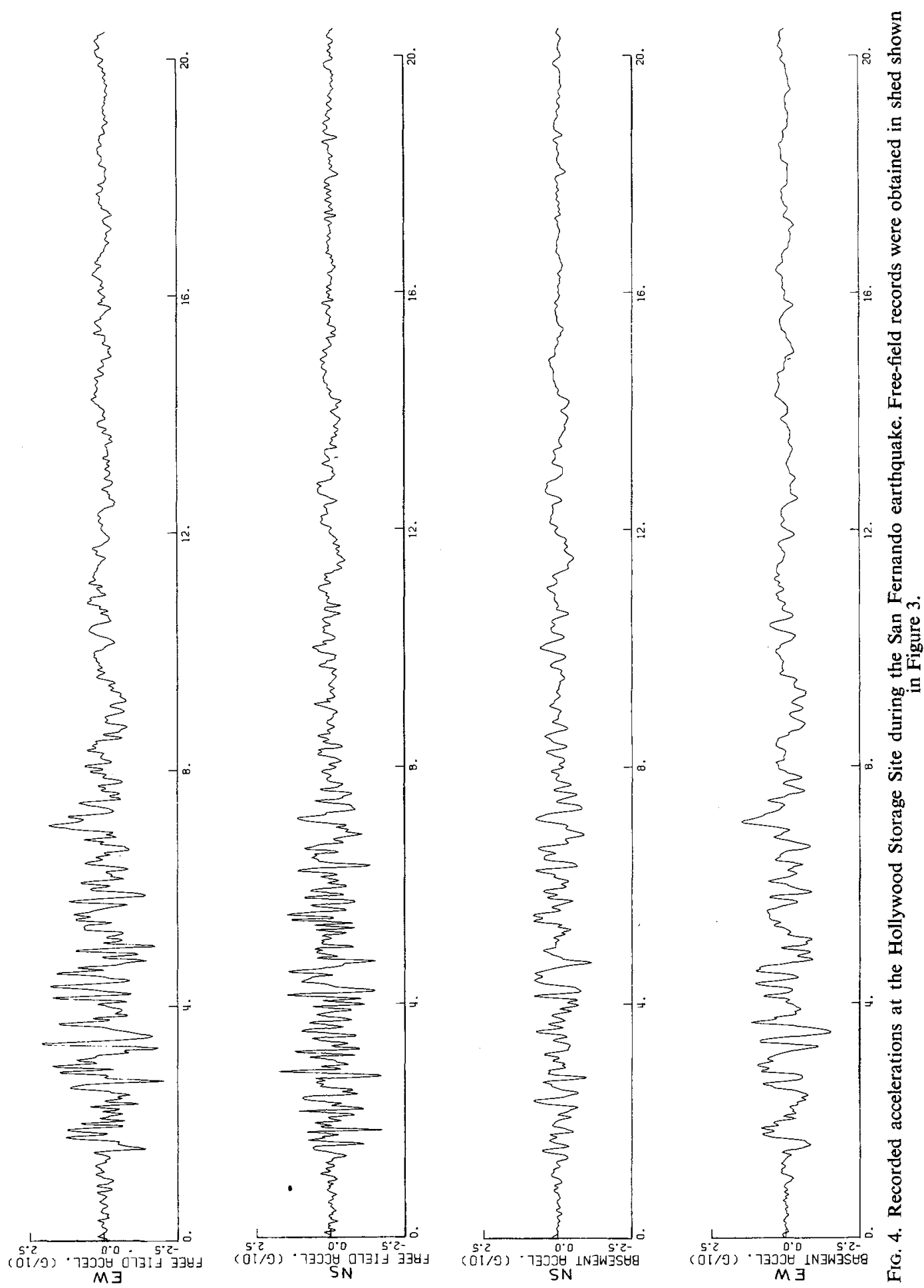



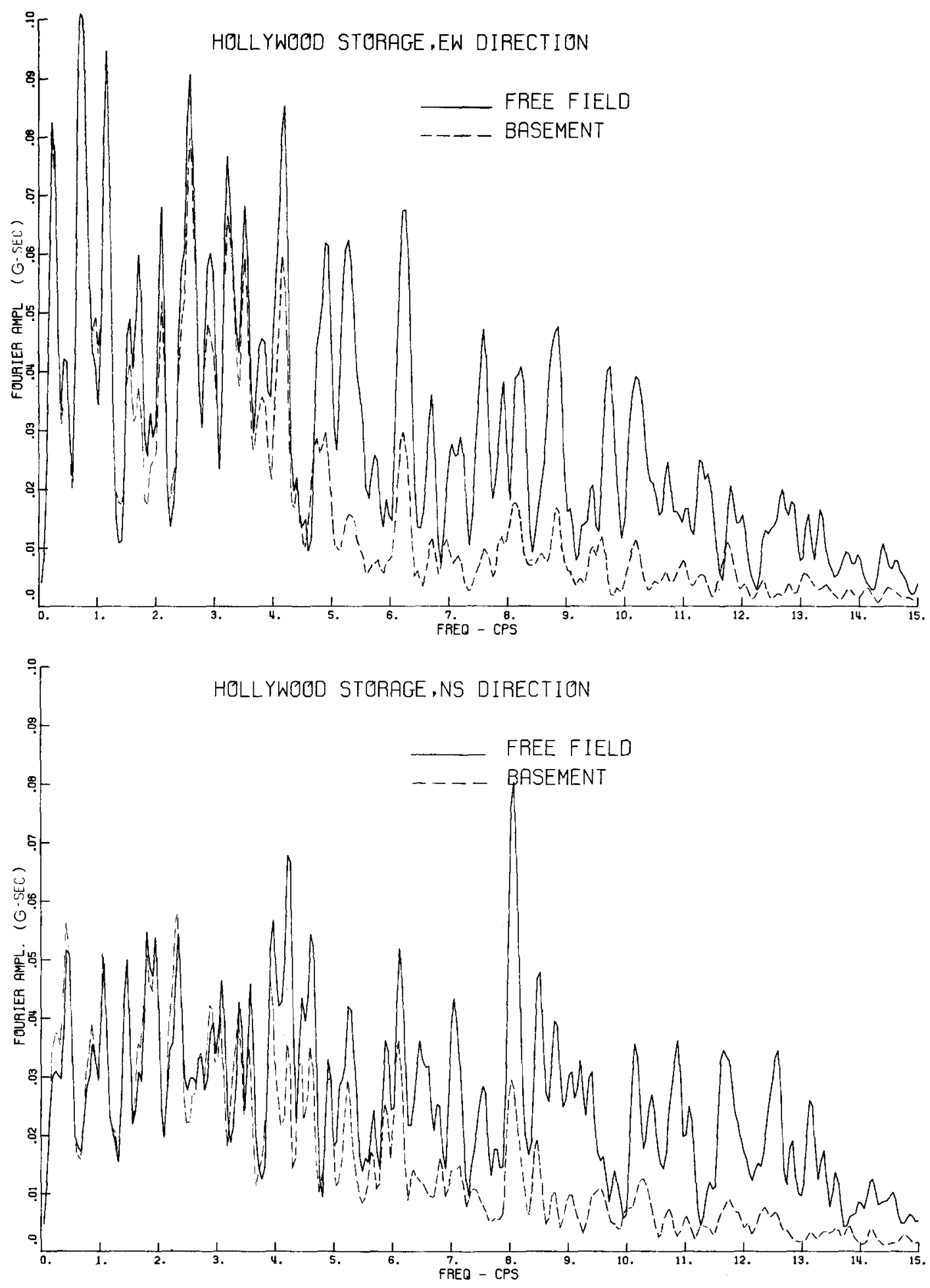

FIG. 5. Fourier Amplitude Spectra of Accelerograms shown in Figure 4. 
frequencies of an appropriate cantilevered shear beam. The EW fundamental frequency from vibration tests was $2.0 \mathrm{~Hz}$ (Carder, 1964).

Figures 6 and 7 compare the basement to free-field transfer functions, $\left|\bar{y}_{o}\right| \overline{\vec{v}}_{g} \mid$, derived from the FAS of the earthquake data and the theoretical model. For the theoretical transfer function the parameters $\rho, V_{s}, a$, and the natural frequencies were fixed. Different choices of the base mass, $m_{o}$, modal damping ratio, $\eta_{j}$, and mode shapes, $X_{i j}$, were made to indicate their effect on the transfer function and to seek good agreement with the measured motion.

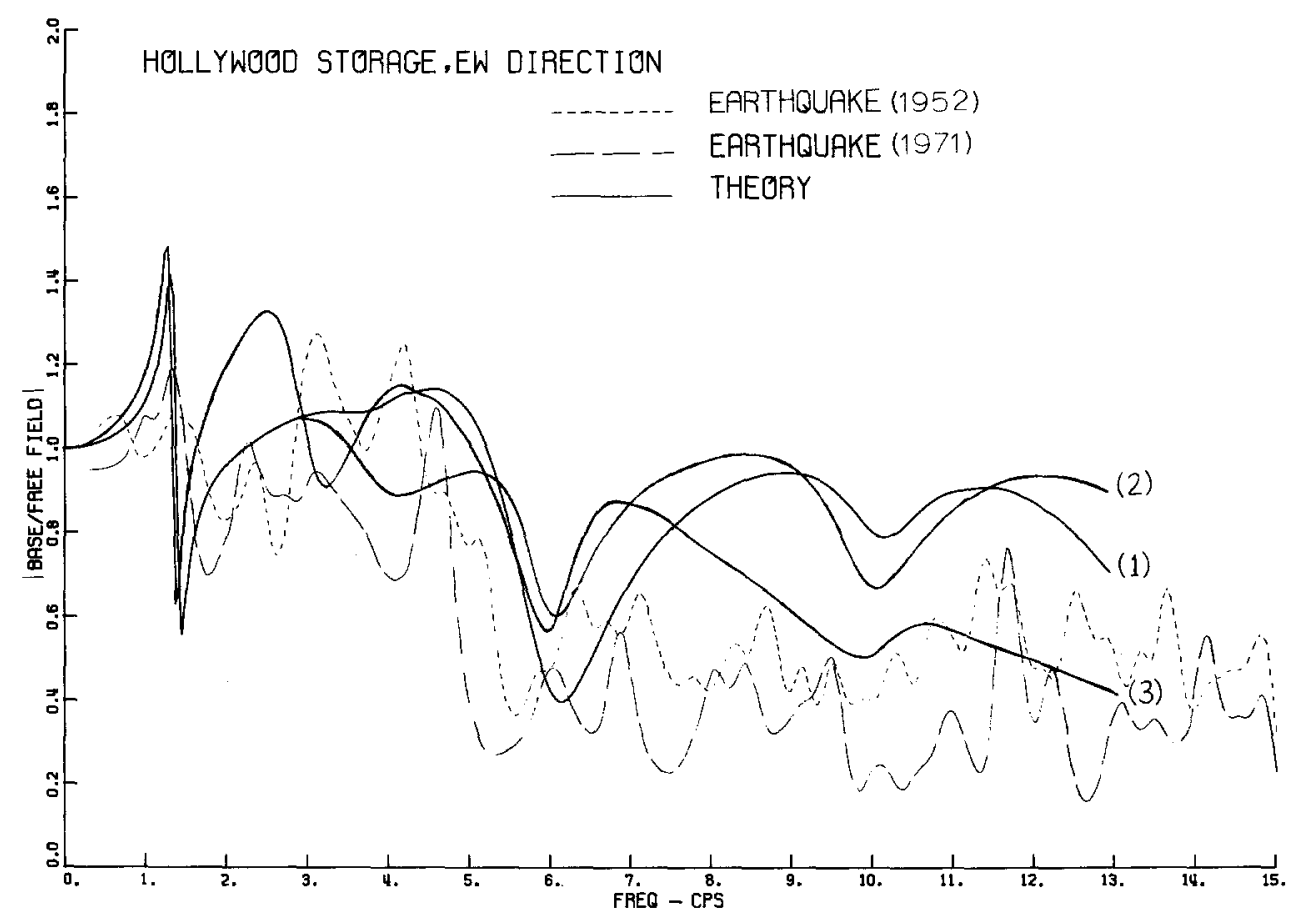

Fig. 6. Comparison of transfer functions. Values of parameters chosen for the theoretical models are: (1) $m_{o}=5 \times 10^{6} \mathrm{lb}$., $I_{t}=1.21 \times 10^{11} \mathrm{lb}-\mathrm{ft}, \eta=0.05$; mode shapes calculated from Duke et al. (1970). (2) $m_{0}=5 \times 10^{6} \mathrm{lb}, I_{t}=1.21 \times 10^{11} \mathrm{lb}-\mathrm{ft}, \eta=0.05$; mode shapes from Jennings et al. (1972). (3) $m_{o}=3.1 \times 10^{7} \mathrm{lb}, I_{t}=2.2 \times 10^{11} \mathrm{lb}-\mathrm{ft}, \eta=0.05$; mode shapes calculated from Duke et al. (1970).

Comparison of the transfer functions determined from the accelerograms recorded in the San Fernando and Arvin-Tehachapi earthquakes gives an indication of the accuracy expected in calculation of an experimental transfer function. There is general similarity in the shapes of the transfer functions, and it is noted that there is a difference, consistent in both earthquakes, in the way the experimentally determined transfer functions decay in the two directions with increasing frequency. The functions decay rapidly around $5 \mathrm{~Hz}$ for the long, EW direction, whereas the decay is more gradual for the shorter NS direction of the building. The transfer functions do not compare so well in detail; the locations of many of the peaks match, but many do not. In addition, the transfer functions found from the weaker motions in the Arvin-Tehachapi earthquake are consistently higher than those found from the San Fernando records for higher frequencies.

Figure 6 shows how two different sets of mode shapes can affect the shape of the theoretical transfer function. The amplitude of the distortions in the transfer function from higher modes, through the modal quantities, $M_{j}, \bar{I}_{j}, H_{j}$, depends significantly on the mode shapes. Such variations are more pronounced for the higher modes, where the 


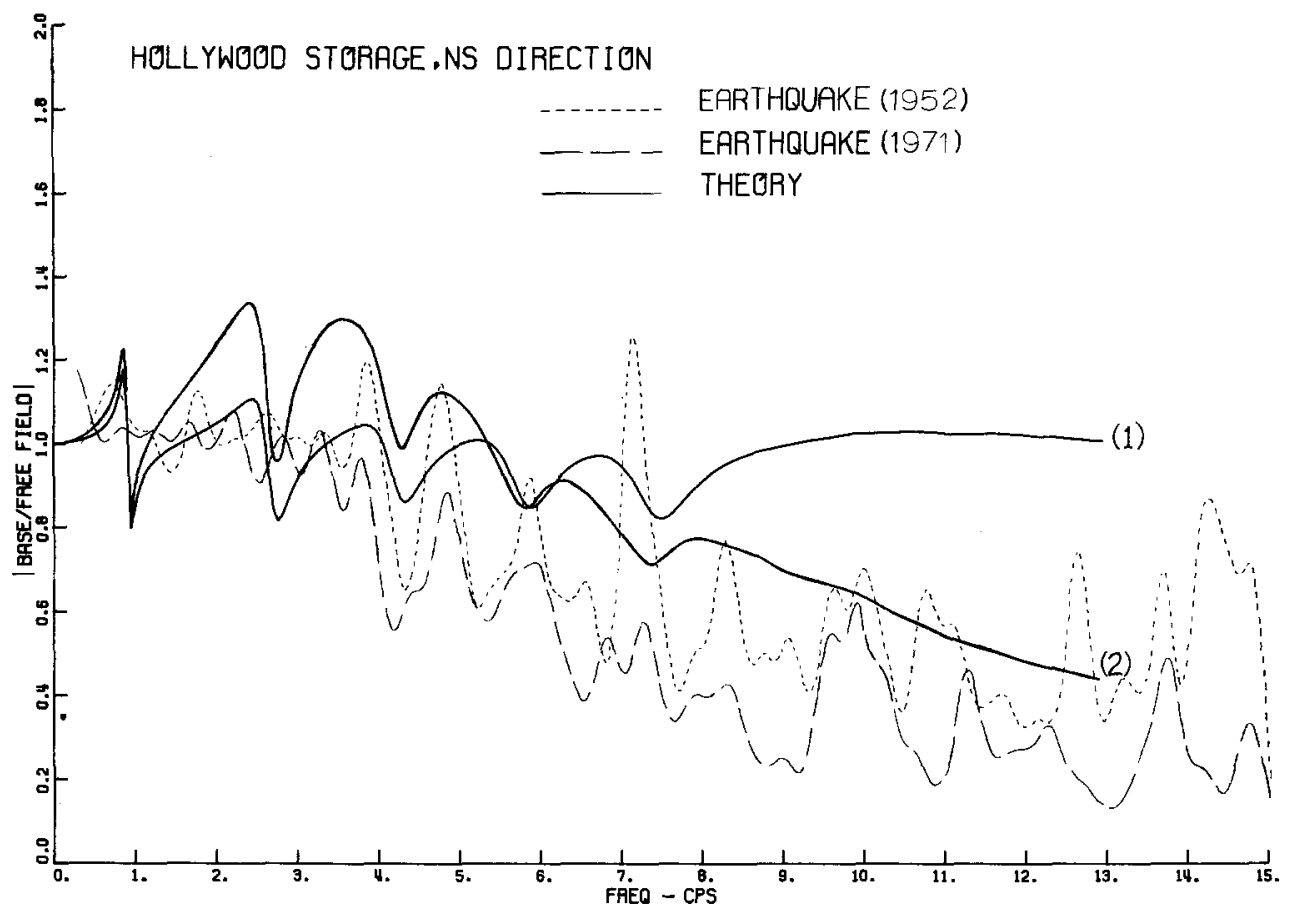

Fig. 7. Comparison of transfer functions. Values of parameters chosen for the theoretical models are: (1) $m_{o}=5 \times 10^{6} \mathrm{lb}, I_{t}=6.7 \times 10^{9} \mathrm{lb}-\mathrm{ft}, \eta=0.05$; mode shapes calculated from Duke et al. (1970). (2) $m_{o}=3.1 \times 10^{7} \mathrm{lb}, I_{t}=1.22 \times 10^{10} \mathrm{lb}-\mathrm{ft}, \eta=0.05$; mode shapes calculated from Duke et al. (1970).

distortions are spread over a wider frequency band than they are at the fundamental frequency.

A comparison of the theoretical transfer functions in Figures 6 and 7 shows the basement response greatly attenuated at high frequencies by a six-fold increase in the base mass. The smaller value of $m_{o}, 5 \times 10^{6} \mathrm{Ibs}$, is an estimate of the weight of the basement and ground-level floor slabs and the weight of the concrete walls in the basement. The larger value, $m_{o}=3.1 \times 10^{7} \mathrm{lbs}$, includes an estimate of the weight of the soil and clustered foundation piles between the basement floor and the rock layer on which they bear. This value of the base mass was thought to be an upper bound for $m_{0}$.

An example of how the modal damping, $\eta_{j}$, affects the transfer function is not included because the effect is relatively minor (Crouse, 1973). Larger values of $\eta_{j}$ tend to smooth the distortions for all modes; but, as might be expected, moderate variations in $\eta_{j}$ do not alter the overall shape of the transfer function.

The partial agreement between the theoretical and actual transfer functions in the EW direction is limited to frequencies between 0 and about $5 \mathrm{~Hz}$. There is some evidence of soil-structure interaction in the fundamental mode for the San Fernando earthquake. The San Fernando transfer function near $1.5 \mathrm{~Hz}$ conforms in shape and size with the doublets in the theoretical transfer functions near this frequency. The theoretical doublets occur at somewhat lower frequencies than shown by the San Fernando data indicating, perhaps, that the value of $800 \mathrm{ft} / \mathrm{sec}$ used in the analysis is too low. The transfer function from the Arvin-Tehachapi earthquake does not confirm this agreement at the fundamental mode, although there is enough correspondence of the experimental and theoretical transfer functions in the 1.2 to $2.5 \mathrm{~Hz}$ range to conclude that the data are at least not contradictory in this frequency range. Beyond $5 \mathrm{~Hz}$, it does not appear that any combination of parameters used in the analysis will produce good agreement with the observed 
behavior. Using the upper bound for $m_{o}$ in the theoretical model will attenuate the amplitude of the transfer function enough to give reasonable agreement for frequencies beyond $11 \mathrm{~Hz}$ for the San Fernando data (Figure 6). The amplitude of the Arvin-Tehachapi transfer function shows reasonable agreement with this theoretical curve for frequencies beyond $4 \mathrm{~Hz}$. In both cases, however, the choice of the larger $m_{o}$ reduces the agreement in the low-frequency range.

The theoretical and earthquake transfer functions for the NS direction have about the same amplitude for frequencies between 0 and $4 \mathrm{~Hz}$ if the smaller base mass, $m_{o}=$ $5 \times 10^{6} \mathrm{lbs}$, is selected (Figure 7). Neither of the earthquake transfer functions, however, gives clear indications of interaction in any of the modes, particularly the fundamental. For frequencies beyond $4 \mathrm{~Hz}$, both earthquake transfer functions attenuate in roughly the same manner, with the amplitude levels of the Arvin-Tehachapi slightly larger on the average than the San Fernando earthquake. Using the upper limit for $m_{o}$ improves the agreement for larger frequencies but worsens the agreement for frequencies less than $4 \mathrm{~Hz}$, as was the case in the EW direction.

Comparisons also were made between the San Fernando free-field accelerogram and a theoretical free-field accelerogram. The theoretical free-field accelerogram was computed by transforming the San Fernando EW basement accelerogram through theoretical transfer functions by appropriate Fourier analysis and synthesis. Two theoretical transfer functions, curves 2 and 3 from Figure 6, were selected because of their dissimilarity. Figure 8 clearly shows that the differences between the computed free-field and recorded basement motions are relatively minor, although variations do exist in the size and shape of a few peaks. The similarity of the theoretical free-field motions to each other and to the measured basement record indicates that the differences of transfer functions 2 and 3 from unity (Figure 6) in the frequency band that contains most of the energy of the basement record ( 0 to $4.5 \mathrm{~Hz}$ ) are not large enough to be significant. The theoretical freefield motions are quite different in appearance from the assumed free-field motion recorded in the nearby shed (Figure 4). The differences are, however, confined to frequencies greater than $4.5 \mathrm{~Hz}$, as can be seen in the upper part of Figure 5.

Millikan Library and Athanaeum. The Millikan Library and the Athenaeum buildings are located on the main campus of the California Institute of Technology in Pasadena, approximately 21 miles southeast of the center of energy release during the San Fernando earthquake. The Athenaeum is $1220 \mathrm{ft}$ due east of the Millikan Library.

The Millikan Library is a nine-story, reinforced concrete building, $144 \mathrm{ft}$ tall with a basement level $14 \mathrm{ft}$ below the ground floor. Figure 9 shows a view of the building and some foundation details (Kuroiwa, 1967).

The Athenaeum is a $2 \frac{1}{2}$-story, reinforced concrete structure of fairly complex geometry (Figure 10). The building is asymmetric and nonuniform in height. The basement floor area is approximately 127 by $138 \mathrm{ft}$, with an additional 69 by $32 \mathrm{ft}$ on the north side. The foundation consists of conventional spread footings, 7 by $7 \times 2 \mathrm{ft}$ thick on the average. Both the Library and the Athenaeum rest on alluvium composed of firm to dense sand mixed with gravel with an average weight density of $115 \mathrm{lb} / \mathrm{ft}^{3}$. The alluvium extends about $900 \mathrm{ft}$ to bedrock. A $P$-wave velocity of $2200 \mathrm{ft} / \mathrm{sec}$ to a depth of $100 \mathrm{ft}$ was determined by experimental tests (Duke and Leeds, 1962).

An SMA-1 accelerograph recorded the basement accelerations at the Athenaeum, and an RFT-250 obtained a record in the basement of Millikan Library. Figure 11 compares the lateral components of the basement acceleration of each building, while Figure 12 shows the FAS of 20.48-sec portions of the accelerograms. The FAS plots have been smoothed 10 cycles with the Hanning spectral window. Both the accelerograms and the FAS show that the basement motion was more intense in Millikan than at the Athenaeum, 

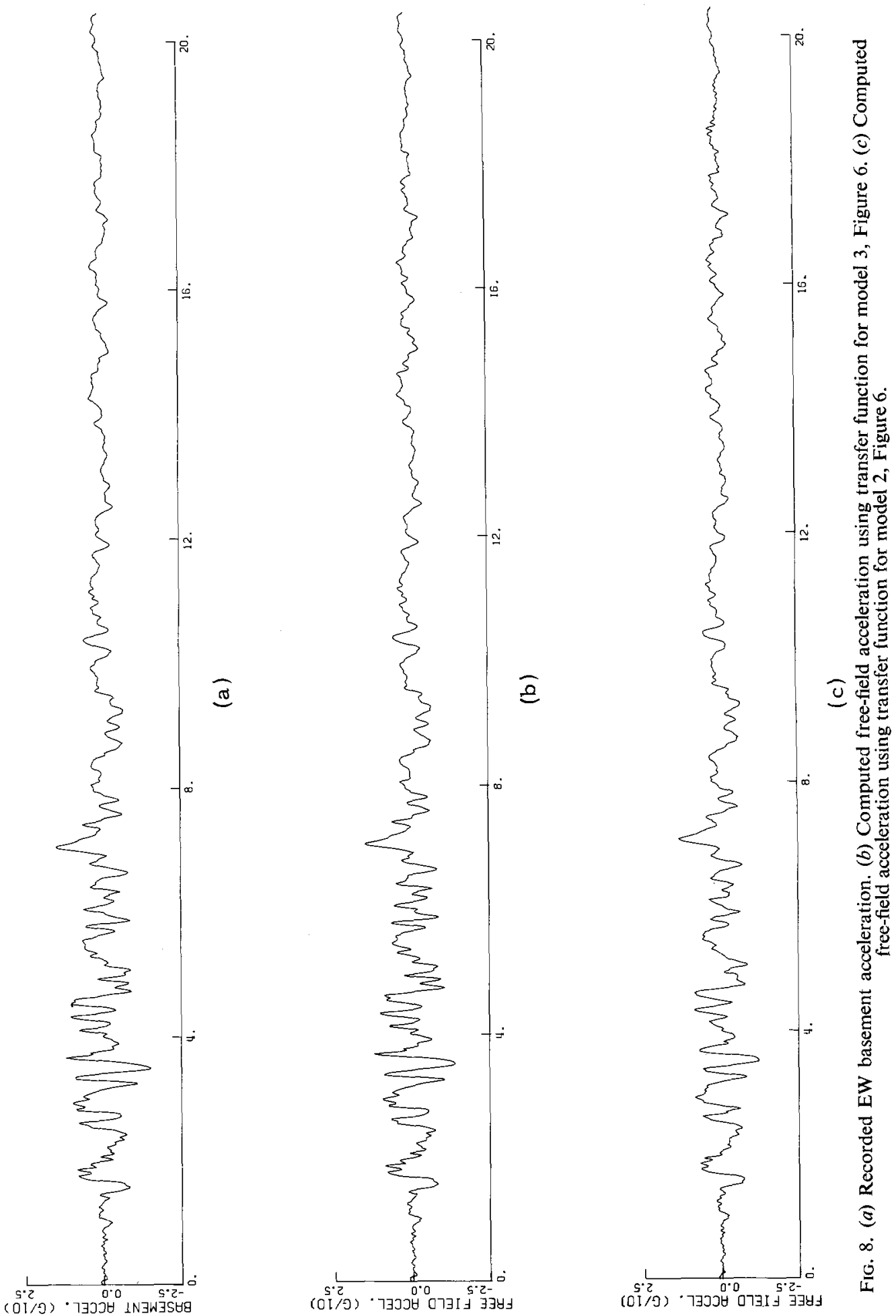


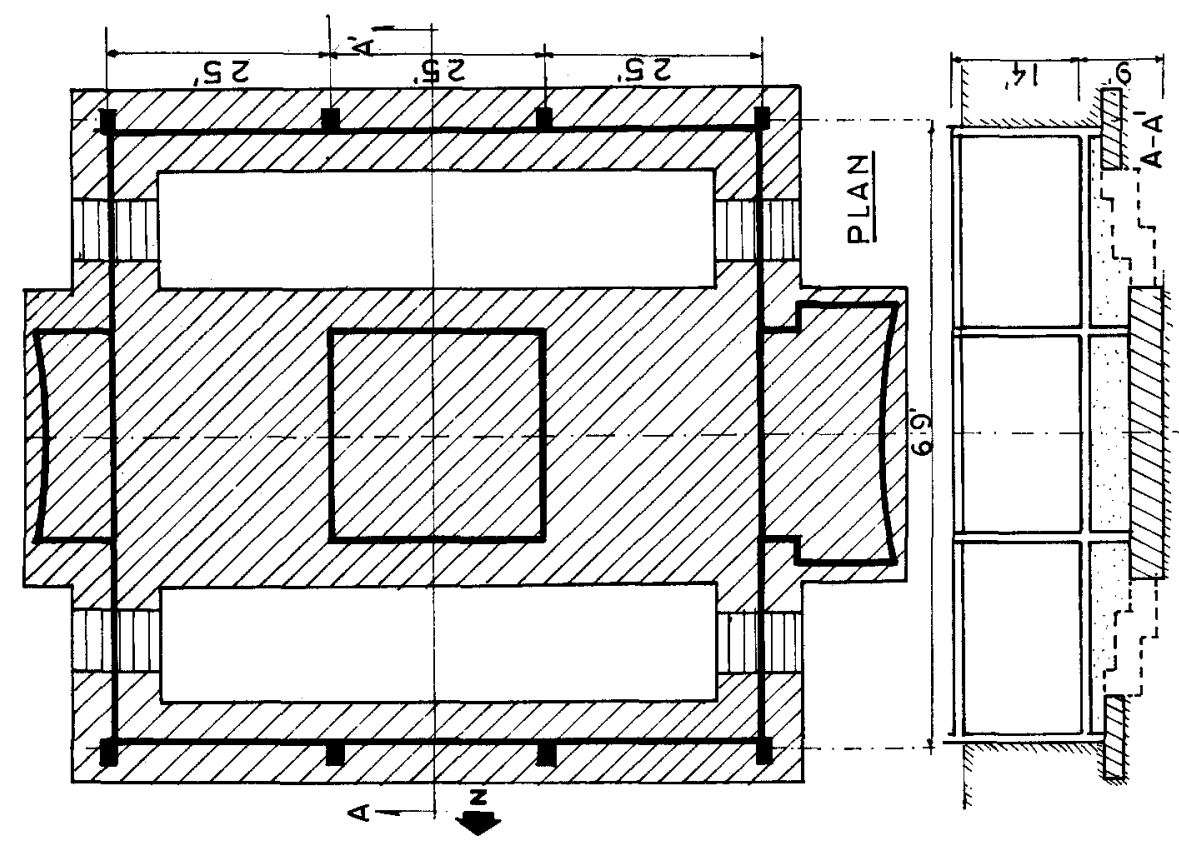

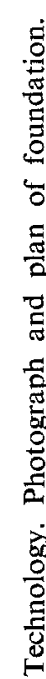

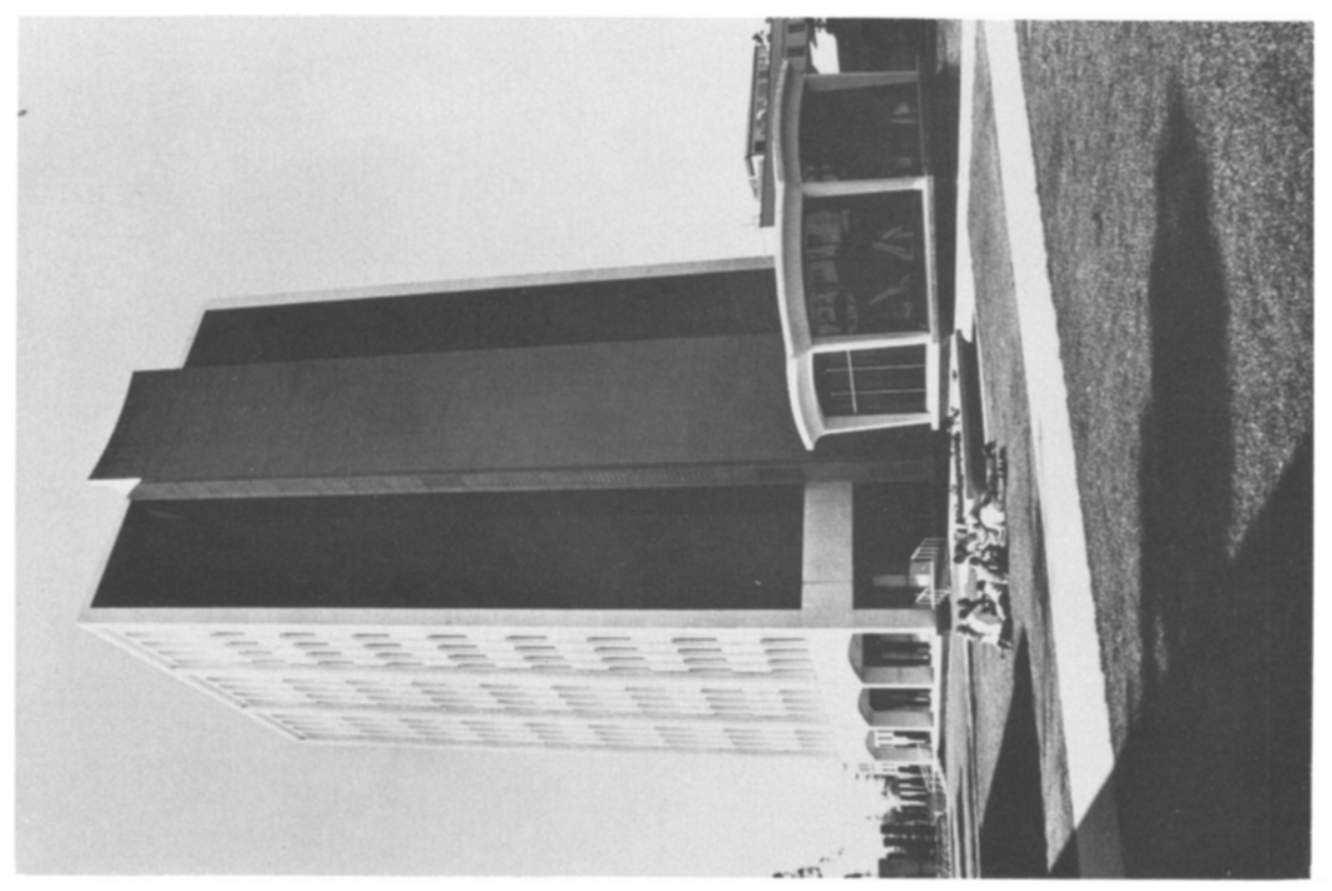


especially in the NS direction. This dissimilarity in accelerograms obtained so close together was widely noted soon after the records became available. It has been suggested that the difference may have been caused by soil-structure interaction (e.g., Richter, 1972).

The Athenaeum was modeled two ways because of its relatively high stiffness. One method was to consider the entire building as a rigid plate; the other way was to approximate it as an equivalent one-story structure resting on a foundation base mass. The weight of the building and foundation determined from structural drawings was $18 \times$ $10^{6} \mathrm{lbs}$. For the single-story approximation, the total weight was divided so that the base mass, $m_{o}$, weighed $13 \times 10^{6} \mathrm{lbs}$ and the first story, $m_{1}, 5 \times 10^{6} \mathrm{lbs}$. The height between $m_{o}$ and $m_{1}$ was estimated to be $20 \mathrm{ft}$. The equivalent base radius was $80 \mathrm{ft}$. A fundamental frequency of $4 \mathrm{~Hz}$ was chosen for both directions and the modal damping was assumed to be 5 per cent of critical.

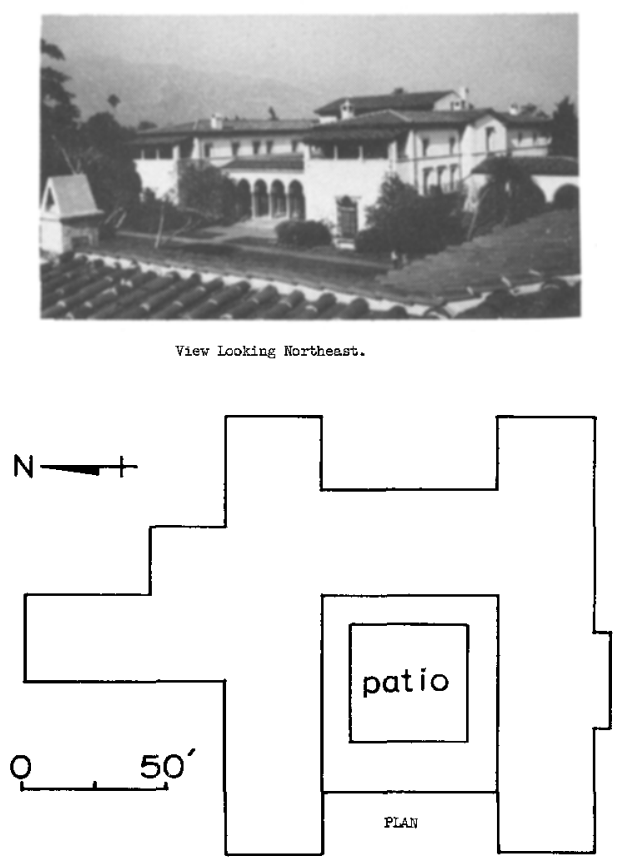

FIG. 10. Athenaeum, California Institute of Technology.

The masses of each story for the Millikan Library were taken from Kuroiwa (1967). The total weight of the superstructure, $18.7 \times 10^{6} \mathrm{lbs}$, is divided fairly evenly among the nine stories. Values estimated for the weight of the base mass and radius were $7 \times 10^{6} \mathrm{lbs}$ and $45.9 \mathrm{ft}$, respectively. The fundamental frequencies, based on pre-earthquake ambient and forced-vibration tests (Kuroiwa, 1967) were $2.0 \mathrm{~Hz}$ (NS direction) and $1.5 \mathrm{~Hz}$ (EW direction). The tests showed the 2nd natural frequency in the EW direction to be $6.2 \mathrm{~Hz}$. The third EW natural frequency was arbitrarily chosen as $13.5 \mathrm{~Hz}$. The second natural frequency in the NS direction, $10 \mathrm{~Hz}$, was based on the FAS of accelerograms from the roof and basement (Wood, 1972). Fundamental mode shapes for the superstructure were taken from Kuroiwa's forced-vibration tests.

To complete the modeling of the superstructure, interstory stiffnesses were calculated from the fundamental frequency and mode shape plus the story masses. The formula 

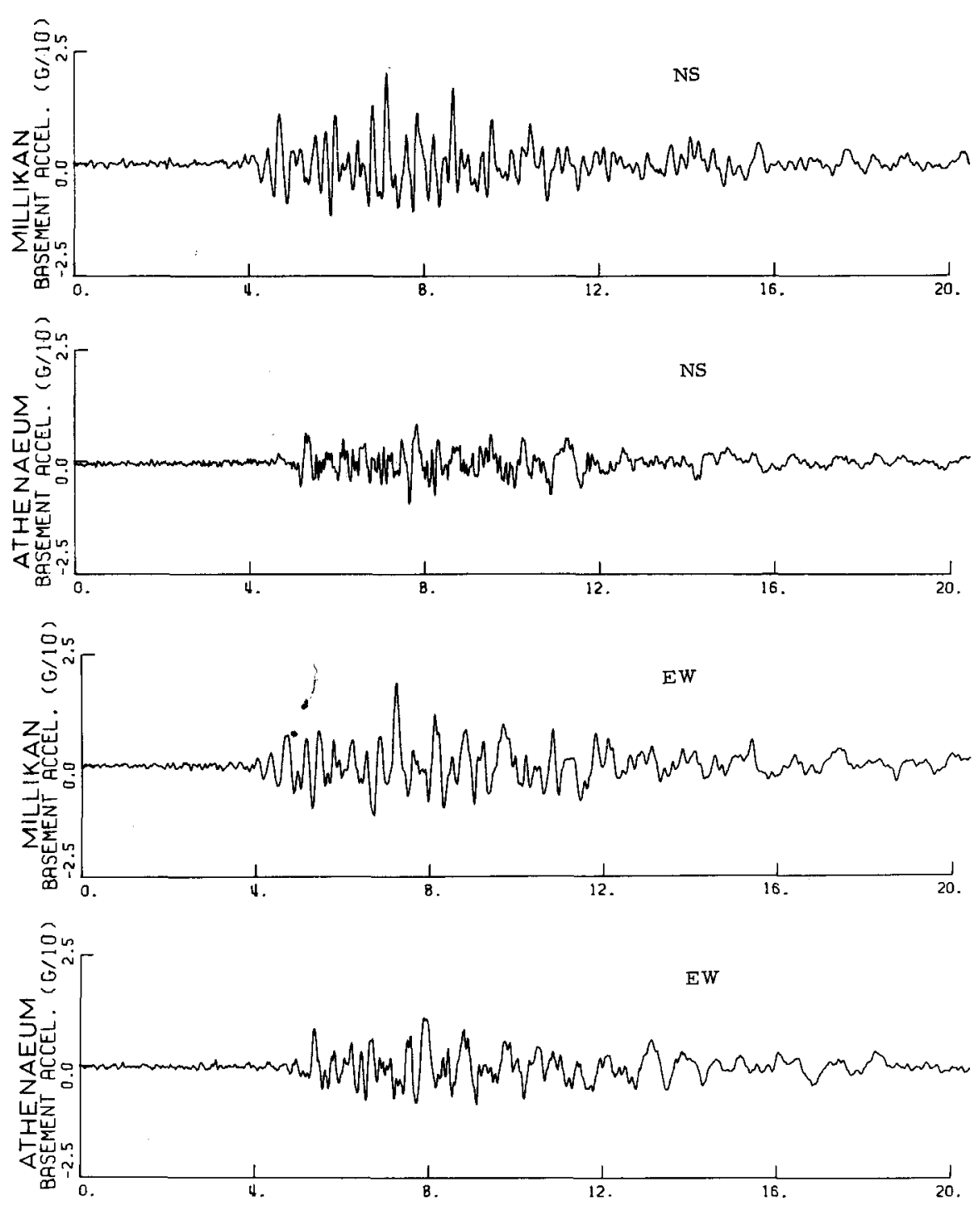

FIG. 11. Comparison of recorded accelerograms from the Millikan Library and Athenaeum.

used to estimate the interstory stiffnesses (Nielsen, 1964) was

$$
k_{s}=\frac{\omega_{1}^{2} \sum_{i=1}^{n} m_{i} X_{1, i}}{X_{1, s}-X_{1, s-1}}, \quad s=1,2, \ldots, n
$$

where $\omega_{1}$ is the fundamental frequency in radians per second, and $m_{i}$ is the mass of the $i^{\text {th }}$ story. Knowledge of interstory stiffnesses and mass of each story enabled the calculation of the higher mode shapes by solving the eigenvalue problem. The higher natural frequencies obtained from the solution did not agree very well with the values mentioned previously, thus indicating a discrepancy between the calculated and actual stiffnesses. However, the effect of these differences on the mode shapes and, hence, the theoretical transfer function will not be significant when comparisons are made with the transfer function calculated from the earthquake data. 

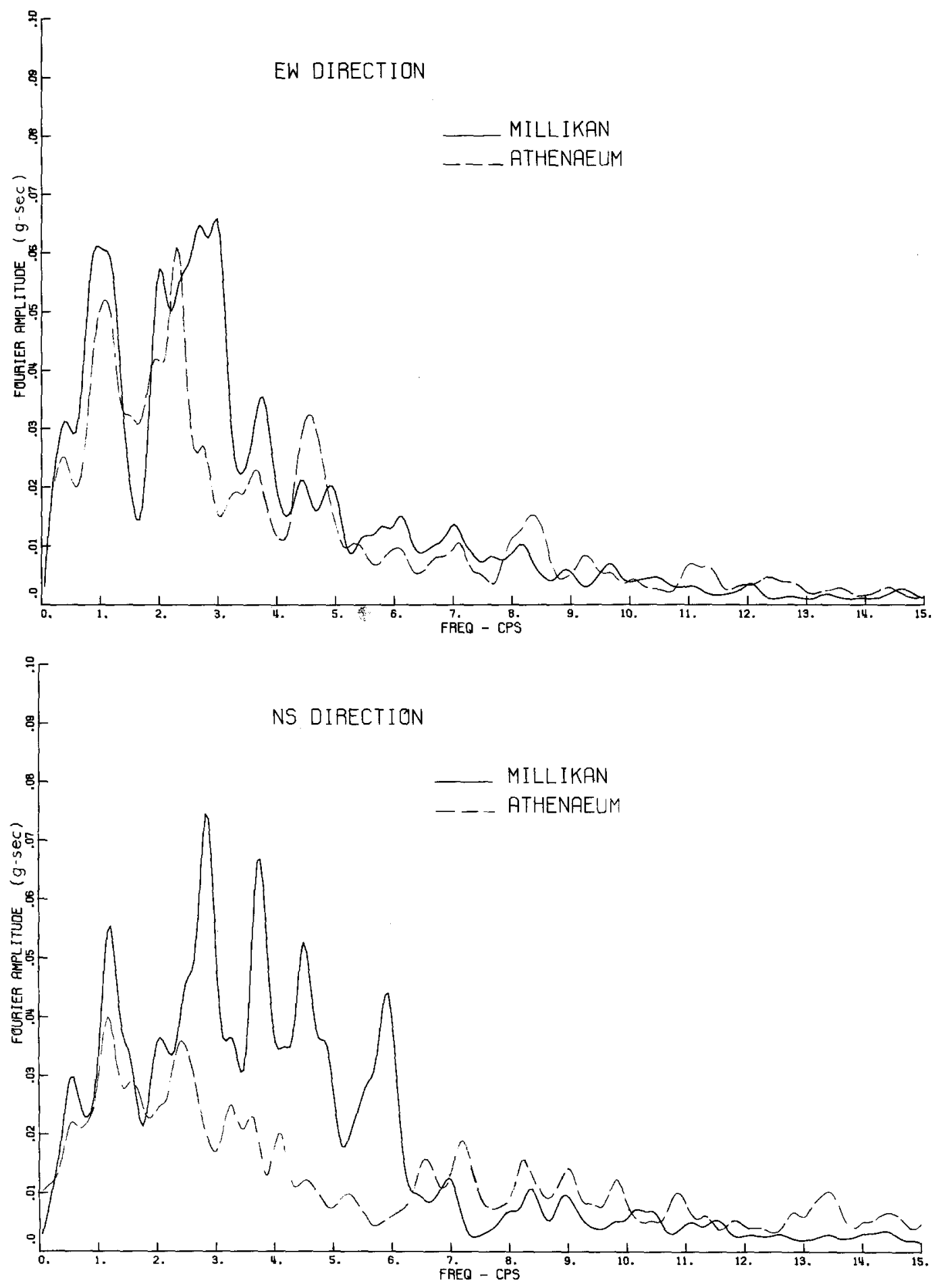

FIG. 12. Fourier amplitude spectra of accelerograms shown in Figure 11. 
Soil parameters used were the same for both soil-structure systems. Values for the unit weight of the soil and Poisson's ratio were $\rho=115 \mathrm{lb} / \mathrm{ft}^{3}$ and $\sigma=0.25$. For strain levels associated with earthquake response, an approximate shear-wave velocity of $800 \mathrm{ft} / \mathrm{sec}$ was estimated in a manner similar to that done for the Hollywood Storage site.

To test whether soil-structure interaction could account for the differences noted in the FAS and the accelerograms, the free-field motions near each building were assumed to be identical. For vertically incident waves this would be a valid assumption discounting any local geological irregularities and the influence of other nearby structures. The modulus of a transfer function, $\left|\bar{y}_{o}(\omega) / \overline{\vec{v}}_{g}(\omega)\right|$, was calculated for each building. The moduli were then divided to give the amplitude of a theoretical transfer function between the basements of each building, i.e.,

$$
+\left|\overrightarrow{\ddot{y}}_{o}(\omega)_{\text {MiLlikan }} / \overrightarrow{\ddot{y}}_{o}(\omega)_{\text {Athenaeum }}\right| \text {. }
$$

The amplitude of this transfer function was then compared with the ratio of the FAS calculated from the accelerograms.

Theoretical transfer functions, $\left|\tilde{\ddot{y}}_{0}(\omega) / \overline{\hat{v}}_{g}(\omega)\right|$, are shown in Figure 13. Model 2 in Figure $13 \mathrm{a}$ represents the Athenaeum treated as a rigid circular plate with a weight equal to the total weight of the building. The curve is nearly flat, implying that the basement and freefield motions are essentially identical. No reasonable increase in base mass or moment of inertia, for example by including the weight of the soil between the bottom of the footings and basement floor, could alter the Athenaeum's theoretical transfer function enough so that the theoretical free-field motion would be noticeably different from the basement motion. Based on the analysis of the Hollywood Storage Building, it can also be concluded that the Millikan Library transfer function would not produce significant differences between the recorded basement motion and theoretical free-field motion, because the transfer function is fairly close to unity over a frequency range containing most of the energy of the strong motion. Thus, the theoretical free-field accelerograms for the Millikan Library and the Athenaeum are essentially the same as their respective basement accelerograms.

Figure 14 compares the ratio of theoretical transfer functions to the ratio of the basement FAS smoothed an additional 10 cycles. The agreement between the theoretical ratios and those from the earthquake response is poor for frequencies beyond $2 \mathrm{~Hz}$, particularly for the NS direction. There does not appear to be any reasonable way to adjust the parameters of the soil-structure model of either building to improve the agreement substantially. The agreement could be improved somewhat, mainly in the EW direction, if the peaks in the theoretical curves at $4 \mathrm{~Hz}$ were relocated at $3 \mathrm{~Hz}$. This would be the case if the fundamental NS and EW frequencies of the Athenaeum were $3 \mathrm{~Hz}$. Ambient measurements of the Athenaeum were made on June 20, 1974 to investigate this possibility. The building is not very suitable for ambient testing, but the results of this preliminary test indicated NS and EW fundamental frequencies of about $2.5 \mathrm{~Hz}$. Although possible, it seems unlikely that the fundamental frequencies are near $3 \mathrm{~Hz}$ for earthquake response.

\section{DisCUSSION}

Comparisons of data and analysis for the Hollywood Storage Building are not conclusive, but it does appear probable that soil-structure interaction occurred in the EW fundamental mode during the San Fernando earthquake. The data from the ArvinTehachapi earthquake are not contradictory to this conclusion, but do not by themselves suggest significant interaction in this mode. The theoretical transfer functions indicate 


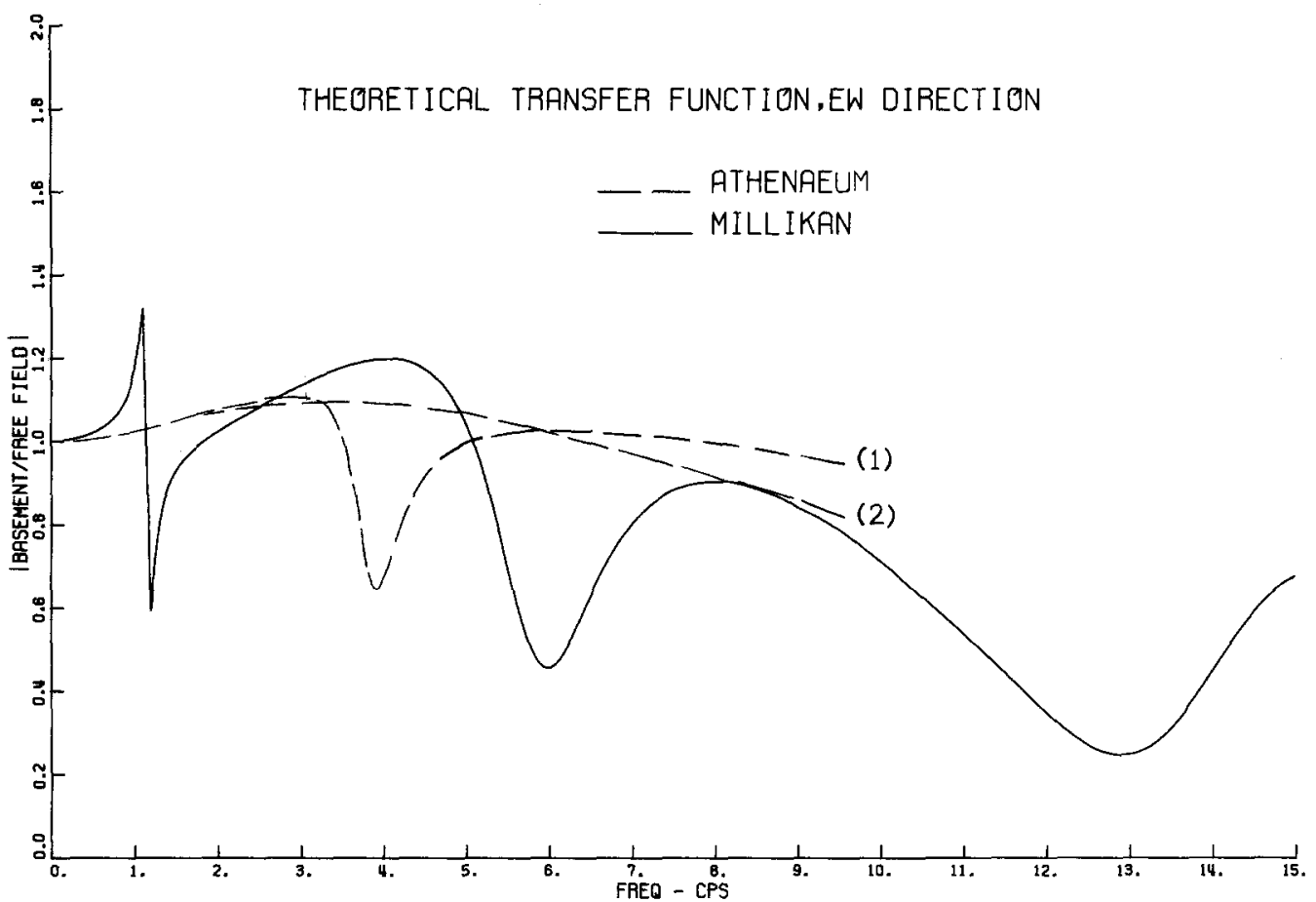

(a)

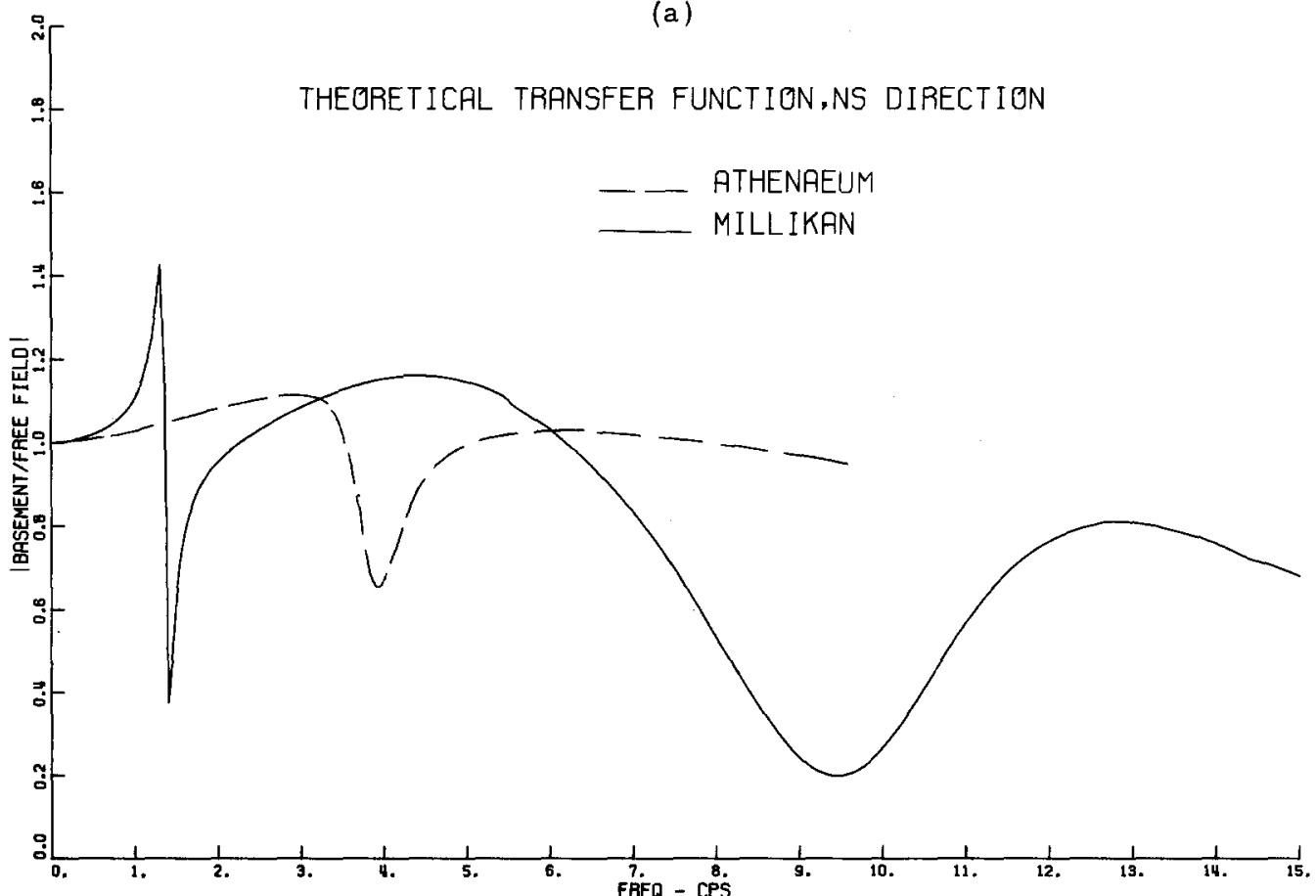

(b)

Fig. 13. Comparison of transfer functions. (a) EW direction. Athenaeum treated as rigid plate, model 2. Athenaeum treated as single-degree-of-freedom system, model 1. (b) NS direction. Athenaeum treated as single-degree-bf-freedom system. 


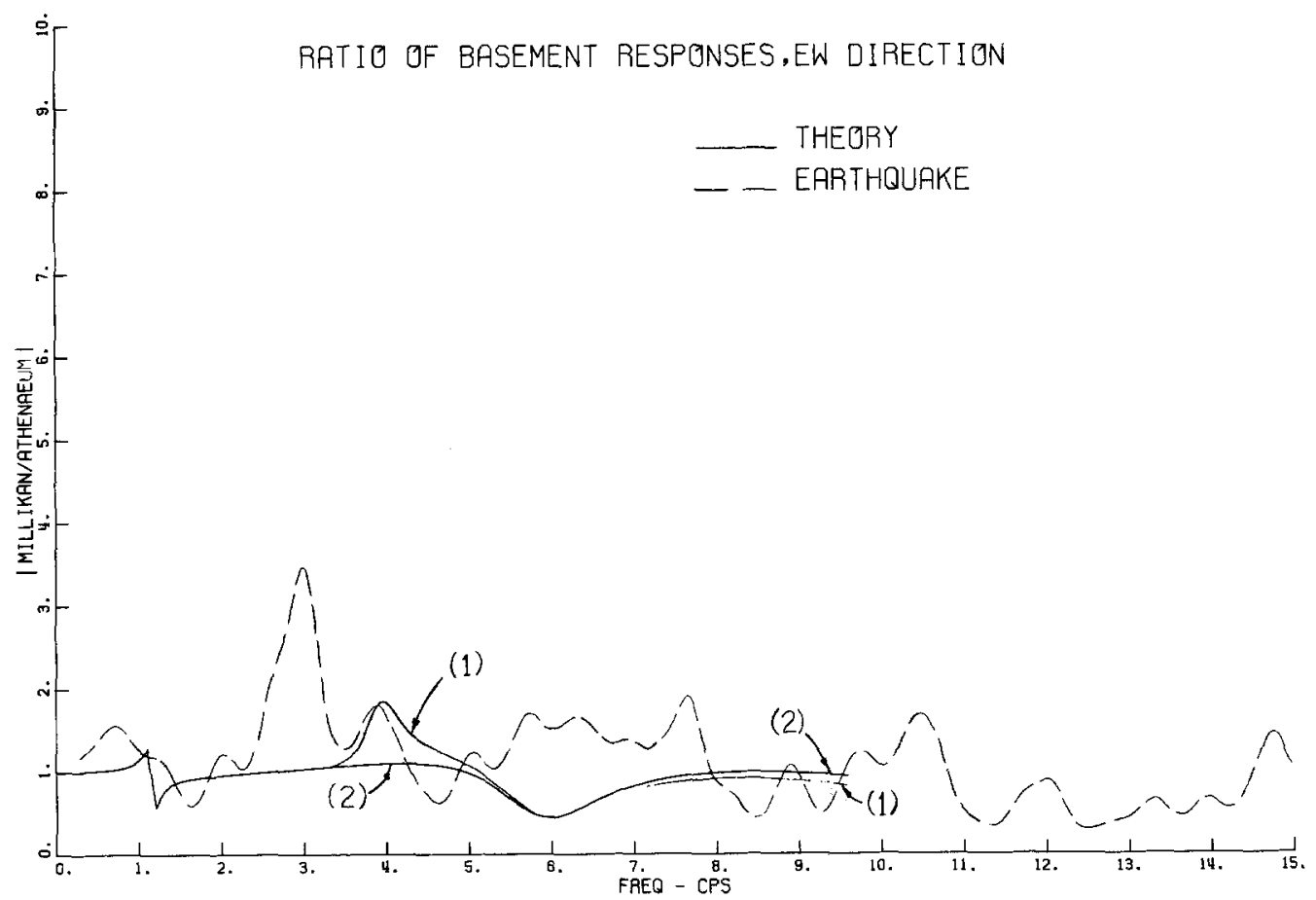

(a)

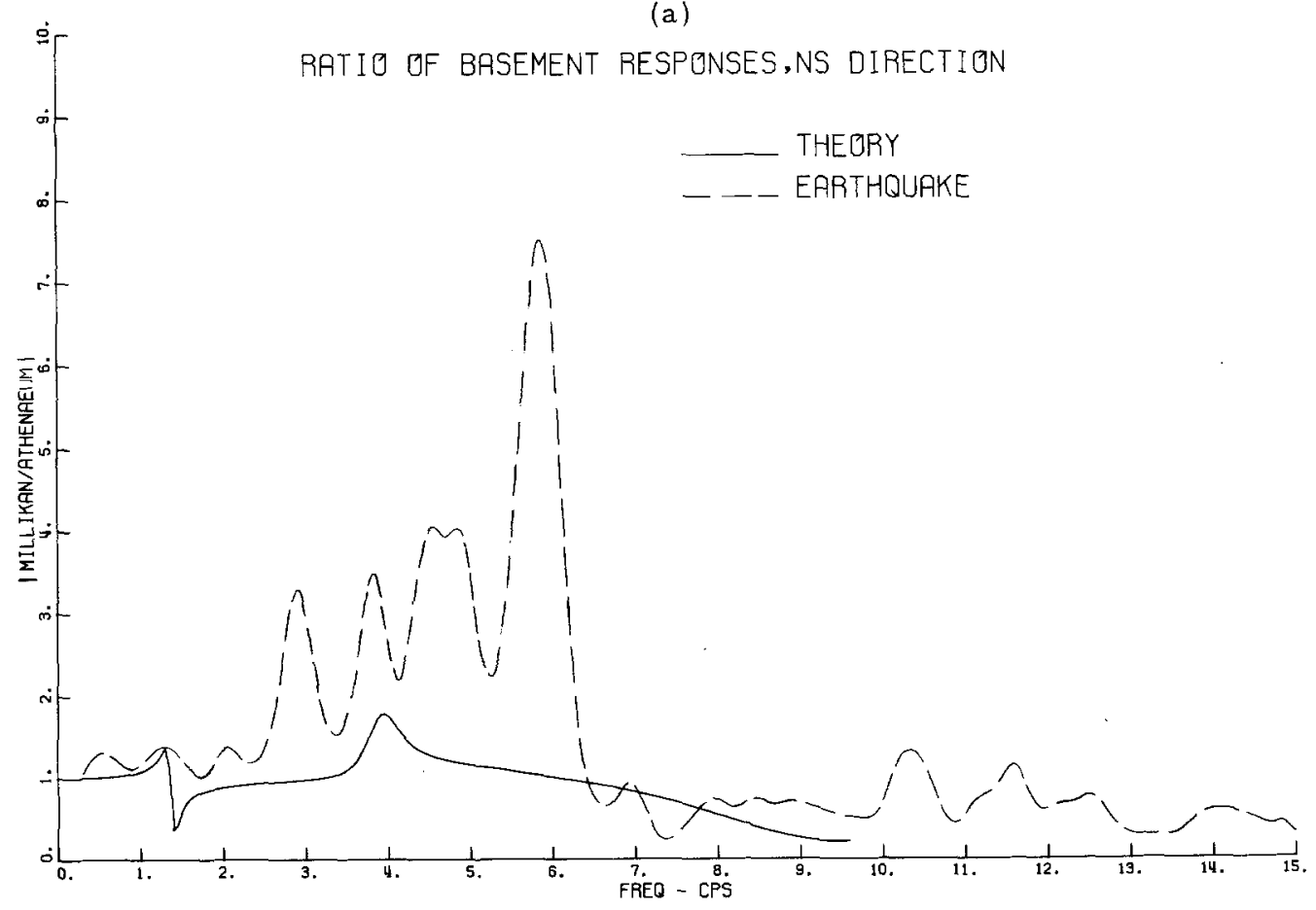

(b)

Fig. 14. Comparison of transfer functions. (a) Theoretical transfer functions calculated from Figure 13a. (b) Theoretical transfer function calculated from Figure $13 \mathrm{~b}$. 
much less interaction for the NS fundamental mode and data from both earthquakes show no identifiable interaction at this frequency. The theoretical and experimental results for the NS direction agree in the sense that their overall level is the same in the important frequency band from 0 to $6 \mathrm{~Hz}$, but they do not agree in detail.

In addition to possible effects at the fundamental frequencies, the attenuation of the experimental transfer functions at higher frequencies and the consistent differences in the rate of attenuation in the NS and EW experimental transfer functions for the two earthquakes are probably caused by interaction. Unfortunately, the degree of accuracy and consistency of the experimentally determined transfer functions limits detailed comparisons with analytical results. As is seen in Figures 4 and 5, the attenuation in the transfer functions arises because the building apparently filtered out the higher frequencies found in the free-field accelerograms. Reasonable variations in the parameters of the theoretical model used were unable to predict this filtering satisfactorily, which occurred for frequencies above about $5 \mathrm{~Hz}$.

There are a number of modifications to the theory that might lead to improved agreement between experimental and theoretical results for the higher frequencies. One obvious revision to the theory would be to replace the circular base plate with a rectangular one with the dimensions of the foundation. According to Sarrazin (1970), the differences in the compliance functions between a 2 by 1 rectangular plate and a circular plate of equal area became large for $a_{0}$ above 2, which corresponds to about $4.3 \mathrm{~Hz}$ for the long

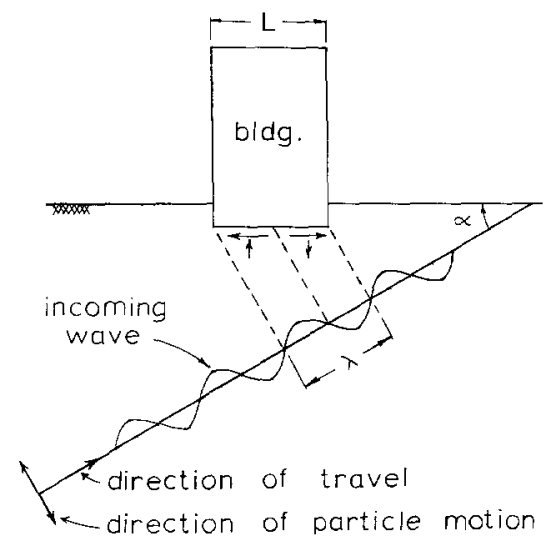

FIG. 15. Filtering by Foundation of a plane harmonic wave incident at an angle.

direction of the Hollywood Storage Building. It may be possible also to approximate this effect of a rectangular foundation using the compliances for a circular base, by selecting the equivalent radius by some procedure other than equating the areas. If the equivalent radius were taken as the length of the foundation in the direction of interest, for example, it can be seen from Figure 2 that the compliances in the two directions would be different and the agreement with the data might possibly be improved.

Another possibility for filtering higher frequencies results from assuming most of the earthquake waves were incident upon the foundation at angles other than vertical. Unfortunately, theories of soil-structure interaction have not yet been developed to treat $P$ or $S V$ waves at arbitrary incidence, or surface waves. The idea of filtering for incident waves can be seen in Figure 15, which shows that for certain wavelengths, $\lambda$, and angles of incidence, $\alpha$, the soil beneath the building tends to move in opposite directions. The foundation would tend to filter out such wavelengths because of its relatively large rigidity. For example, in the case of the EW direction of the Hollywood Storage Building, $L \simeq$ 
$200 \mathrm{ft}$. If the velocity, $v$, and angle of incidence, $\alpha$, of the incoming waves were $800 \mathrm{ft} / \mathrm{sec}$ and $45^{\circ}$, respectively, then the frequency corresponding to the wavelength shown in Figure 15 would be $f=v /(L \cos \alpha) \simeq 5.6 \mathrm{~Hz}$. For waves traveling along the surface at this velocity, $f=4 \mathrm{~Hz}$. For waves from the NS direction, $f$ would be about four times larger since the foundation dimension of the building is only $50 \mathrm{ft}$ in this direction. However, the adjoining one-story structure and the structure $78 \mathrm{ft}$ to the north of the main building might increase the effective length of the building in the NS direction. Although this analysis is approximate, frequencies of filtering are near those observed to be filtered by the building during the earthquake. Similar agreement was obtained by Yamahara (1970) for records obtained in aftershocks of the Tokachi-Oki earthquake. The inability of simplified theoretical models to incorporate waves at arbitrary incidence may be their most serious limitation.

A related mechanism for filtering higher frequencies from the basement records is embedment of the structure, which must become significant for wavelengths of motion comparable to the dimensions of the foundation. In their study of the response of the Hollywood Storage Building during the 1952 earthquake, Hradilek and Luco (1970) modeled the structure and foundation in the long direction by an infinite shear wall mounted on a hemi-cylindrical foundation and on a flat foundation. Their results, shown in Figure 16, indicate much better agreement at higher frequencies for the model with the embedded foundation.

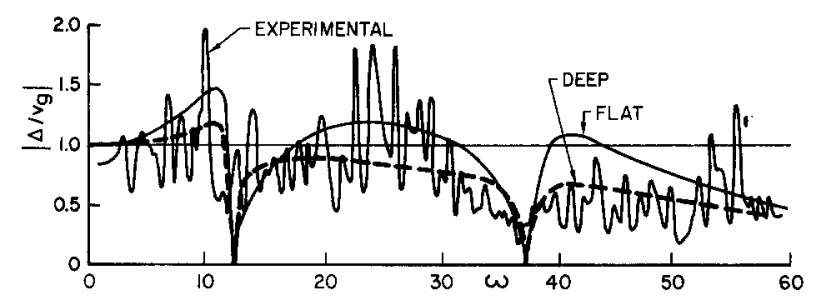

FIG. 16. Comparison of transfer functions for models of the Hollywood Storage Building, EW direction. The curve labeled FLAT is for an infinite shear wall on a flat foundation; DEEP is for the shear wall on a hemi-cylindrical foundation. The experimental result is from the 1952 earthquake. From Hradilek and Luco (1970).

The differences in the experimentally determined transfer functions for the two earthquakes at the site of the Hollywood Storage Building are somewhat larger than might have been hoped. In studying these differences, it was noted that there are some features of the experimental transfer functions that suggest a nonlinear effect in the soil. If the soil had a lower effective modulus during the larger strains experienced in the San Fernando earthquake, the transfer function for the San Fernando event would be lower for higher frequencies, and peaks, in general, would lie to the left of corresponding peaks in the transfer function for the weaker motion of the Arvin-Tehachapi earthquake. These effects are seen to some degree in Figures 6 and 7, but are not convincing and additional measurements are required before more definite statements can be made.

Differences in the experimentally determined transfer functions may also arise if the parking lot records are not representative of the theoretical free-field motion for higher frequencies. The recording site is only one foundation's length removed from the building in the direction of strongest suspected interaction, and it may include, at high frequencies, reflections from the building. Such effects have been noted in theoretical results (e.g., Trifunac, 1972) and could have been studied if the surface motion at other points in the neighborhood of the building had been measured. For sufficiently high frequencies, it is expected that the records from such a set of instruments would show major differences 
and no single record would be representative of the theoretical free-field motion. It should be possible, however, to determine from the records the frequency range over which the concept of free-field motion can be applied.

Some of the observed differences in the accelerograms recorded in Millikan Library and the Athenaeum may also be attributable to the effects noted above, as can be seen from examination of Figure 12. It is possible, for example, that the Athenaeum with its larger foundation is more effective at suppressing waves of higher frequency than is the Library. However, since both buildings are roughly square in plan, the use of an equivalent circle as a base should not be as important a factor for these two buildings as it may be for the Hollywood Storage Building. In addition to differences at higher frequencies, there are also substantial differences in the important frequency band from 0.3 to $2.5 \mathrm{~Hz}$. Although these differences appear in Figure 12, they are best seen in the response spectra shown in Figure 17 (Hudson, 1972; Trifunac et al., 1973). It is seen that the peak at $0.4 \mathrm{sec}$ is absent in the NS spectra from the Athenaeum, and that the spectra of corresponding components at the two sites differ significantly over the entire range from 1 to 3 secs.

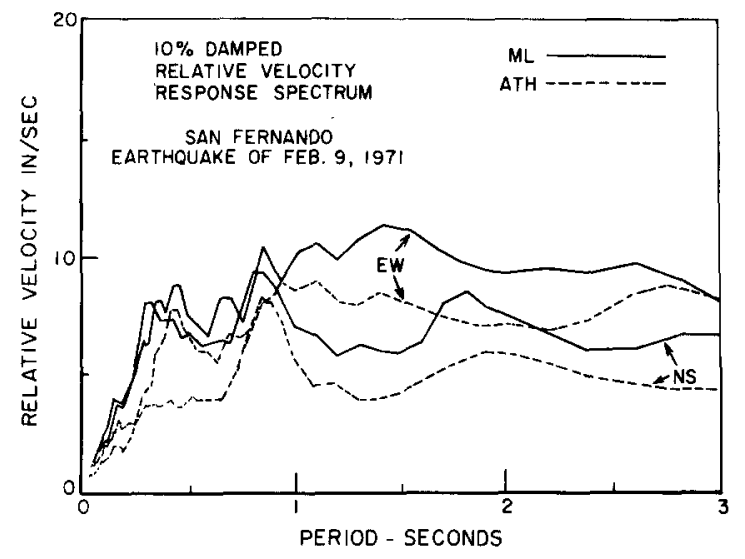

FIG. 17. Response spectra for accelerograms from the Athenaeum and Millikan Library basements, San Fernando earthquake.

The differences at low frequencies in the records obtained in the basements of the Athenaeum and the Millikan Library cannot be explained by existing theories of soilstructure interaction. Some of the difference at higher frequencies may be explained, at least in part, by modifying the theory to incorporate the effects of embedment and scattering. It also seems quite probable that the distance between the buildings and their relative orientation with respect to the epicentral area, coupled with the possibility that many incoming waves may have been incident at angles other than $90^{\circ}$, could account for some of the major differences by different superposition of incoming waves (Crouse, 1973).

For both the Hollywood Storage and campus sites, more records of earthquake response in the bases of the buildings and on the nearby soil are required to answer unresolved questions. In particular, the frequency range over which nearby records are representative of a theoretical free-field motion needs to be determined by measurement. Also, more detailed measurements of foundation motions including rocking and torsion, are required to assess the importance of embedment and other additions to theoretical results.

\section{ACKNOWLEDGMENTS}

The results of this study form a portion of the senior author's doctoral thesis (Crouse, 1973). The financial support of the National Science Foundation and the Earthquake Research Affiliates of the California Institute of Technology during the thesis work is gratefully acknowledged. 


\section{REFERENCES}

Arnold, R. N., G. N. Bycroft, and G. B. Warburton (1955). Forced vibrations of a body on an infinite elastic solid, J. Appl. Mech. 22, 391-400.

Bielak, J. (1971). Earthquake Response of Building Foundation Systems, Earthquake Engineering Research Laboratory, Report EERL 71-04, California Institute of Technology, Pasadena, California.

Bycroft, R. N. (1956). Forced vibration of a rigid circular plate on a semi-infinite elastic space and on an elastic stratum, Phil. Trans. Roy. Soc. London, Ser. A 248, 327-368.

Carder, D. W. (Ed.) (1964). Earthquake Investigations in the Western United States, U. S. Department Commerce, Coast and Geodetic Survey, Publ. 41-2.

Crouse, C. B. (1973). Engineering studies of the San Fernando Earthquake, Earthquake Engineering Research Laboratory, Report EERL 73-04, California Institute of Technology, Pasadena, California.

Duke, C. M. and D. J. Leeds (1962). Site Characteristics of Southern California Strong-Motion Earthquake Stations, Dept. of Eng., University of California at Los Angeles, Report 62-55.

Duke, C. M., J. E. Luco, A. R. Carriveau, P. J. Hradilek, R. Lastrico, and D. Ostrom (1970). Strong earthquake motion and site conditions: Hollywood, Bull. Seism. Soc. Am. 60, 1271-1289.

Gladwell, G. M. L. (1968). Forced trangential and rotary vibrations of a rigid circular disc on a semiinfinite solid, Intern. J. Eng. Sci. 6, 531-607.

Housner, G. W. (1957). Interaction of building and ground during an earthquake, Bull. Seism. Soc. Am. $47,179-186$.

Hradilek, P. J. and J. E. Luco, (1970). Dynamic soil-structure interaction, IDIEM Informa Tecnico No. 14, Instituto de Investigaciones y Ensayes de Materieles, Universidad de Chile, Santiago.

Hudson, D. E. (1972). Local distribution of strong earthquake ground motions, Bull. Seism. Soc. Am. 62, 1765-1786.

Jennings, P. C. (Ed.) (1971). Engineering Features of the San Fernando Earthquake, Earthquake Engineering Research Laboratory Report EERL 71-02, California Institute of Technology, Pasadena, California.

Jennings, P. C., R. B. Matthiesen, and J. B. Hoerner (1972). Forced vibration of a 22-story steel frame building, Intern. J. of Earthquake Eng. and Struct. Dyn. 1, 107-132.

Jennings, P. C. and J. Bielak (1973). Dynamics of building-soil interaction, Bull. Seism. Soc. Am. 63, 9-48.

Kobori, T., R. Minai, T. Suzuki, and K. Kusakabe (1966). Dynamical ground compliance of rectangular foundations, Proc. Japan Natl. Congr. Appl. Mech, 16th.

Kuroiwa, J. H. (1967). Vibration Test of a Multistory Building, Earthquake Engineering Research Laboratory Report, California Institute of Technology, Pasadena, California.

Luco, J. E. and R. A. Westmann (1971). Dynamic response of circular footings, J. Eng. Mech. Div., $A S C E$, 97, EM5, 1381-1395.

Luco, J. E. and R. A. Westmann (1972). Dynamic response of a rigid footing bonded to an elastic half-space, J. Appl. Mech., ASME 39, 527-534.

Lysmer, J. and F. E. Richart (1966). Dynamic response of footings to vertical loading, J. Soil Mech. Found. Div., ASCE, 92, SM1.

Nielsen, N. N. (1964). Dynamic Response of Multistory Buildings, Earthquake Engineering Research Laboratory Report, California Institute of Technology, Pasadena, California.

Novak, M. (1973). Vibrations of embedded footings and structures, Meeting Preprint 2029, ASCE Natl. Struct. Eng. Meeting, San Francisco.

Oien, M. A. (1971). Steady motion of a rigid strip bonded to an elastic half-space, J. of Appl. Mech., ASME 38, 328-334.

Parmelee, R. A., D. S. Perelman, and S.-L. Lee (1969). Seismic response of multiple-story structures on flexible foundations, Bull. Seism. Soc. Am. 59, 1061-1070.

Richter, C. F. (1972). Seismic regionalization or zoning: revision, Proc. Int. Conf. on Microzonation for Safe Construction-Research and Application, Seattle, Washington, 267-282.

Sarrazin, M. A. (1970). Soil-structure interaction in earthquake-resistant design, Research Report R70-59, Department of Civil Engineering, Massachusetts Institute of Technology, Cambridge, Massachusetts.

Seed, H. B. and I. M. Idriss (1970). Soil Moduli and Damping Factors for Dynamic Response Analysis, University of California at Berkeley, Report EERC 70-10, Berkeley, California.

Trifunac, M. D. (1972). Interaction of a shear wall with the soil for incident plane waves, Bull. Seism. Soc. Am. 62, 63-83. 
Trifunac, M. D., A. G. Brady, and D. E. Hudson (1973). Analyses of Strong-Motion Earthquake Accelerograms, Vol. III, Part G, Earthquake Eng. Research Laboratory, Report EERL 73-85, California Institute of Technology, Pasadena, California.

Veletsos, A. S. and Y. T. Wei (1971). Lateral rocking vibration of footings, J. Soil Mech. Found. Div., ASCE 97, SM9, 1227-1248.

Wood, J. H. (1972). Analysis of the earthquake response of a nine-story steel frame building during the San Fernando Earthquake, 'Earthquake Engineering Research Laboratory Report EERL 72-04, California Institute of Technology, Pasadena, California.

Division of ENGineERING AND APPLIED SCIENCE

CALIFornia InSTITUTE OF TeChNOLOGY

Pasadena, California 91109

Manuscript received July 26, 1974.

\section{Notation}

APPENDIX

$M=$ mass matrix of rigid base structure

$C=$ damping matrix of rigid base structure

$K=$ stiffness matrix of rigid base structure

$\ddot{v}_{g} \quad=$ free-field acceleration

$v_{j}=$ horizontal displacement of superstructure at $j^{\text {th }}$ floor relative to the base mass, excluding rotations

$v_{o} \quad=$ translation of base mass relative to free-field motion

$h_{j}=$ height of $j^{\text {th }}$ story above base mass

$\mathbf{v}=\left(v_{j}\right)$, a column vector

$\varphi=$ rotation of base mass

$v_{j}{ }^{t}=v_{g}+v_{o}+h_{j} \varphi+v_{j}$

$m_{j}=$ mass of $j^{\text {th }}$ story

$I_{j} \quad=$ centroidal moment of inertia of $j^{\text {th }}$ mass

$m_{o}=$ base mass

$I_{o}=$ centroidal moment of inertia of base mass

$I_{t} \quad=I_{o}+\sum_{j=1}^{n} I_{j}$

$P(t)=$ horizontal interaction force between base mass and soil

$Q(t)=$ interaction moment between base mass and soil

$\rho \quad=$ mass density of soil

$\sigma=$ Poisson's ratio of soil

$V_{s}=$ shear-wave velocity of soil

$a \quad=$ radius of base mass

$\mu \quad=$ shear modulus of soil $\left(=V_{s}^{2} \rho\right)$

$\mathbf{X}_{k}=k^{\text {th }}$ mode shape of rigid base structure

$X_{j k}=j^{\text {th }}$ component of $\mathbf{X}_{k}$ 
II. Soil-structure interaction transfer functions. The transform parameter, $s$, has been replaced by $i \omega$ for application in equation (6).

$$
\begin{aligned}
& \Delta= \omega^{4} \sum_{\substack{j, k=1 \\
j \neq k}}^{n}\left(M_{j} \bar{I}_{k}-Z_{j} Z_{k}\right) \hat{F}_{j k}(\omega) \\
&- \omega^{2}\left(-\omega^{2} I_{t}+\mu a^{3} K_{m m}\right)\left(\sum_{j=1}^{n} \hat{F}_{j}(\omega) M_{j}\right) \\
&- \omega^{2}\left(-\omega^{2} m_{o}+\mu a K_{h h}\right)\left(\sum_{j=1}^{n} \hat{F}_{j}(\omega) \bar{I}_{j}\right) \\
&+\prod_{k=1}^{n}\left(-\omega^{2}+\omega_{k}^{2}+i 2 \eta_{k} \omega_{k} \omega\right)\left[\omega^{4} m_{o} I_{t}-\mu a^{3} \omega^{2} m_{o} K_{m m}-\mu a \omega^{2} K_{h h} I_{t}+\mu^{2} a^{4} K_{h h} K_{m m}\right] . \\
& \Delta_{o}=-\left[-\omega^{2} \sum_{j, k=1}^{n}\left(M_{j} \bar{I}_{k}-Z_{j} Z_{k}\right) \hat{F}_{j k}(\omega)\right. \\
&+\left(-\omega^{2} I_{t}+\mu a^{3} K_{m m}\right)\left(\sum_{j=1}^{n} \hat{F}_{j}(\omega) M_{j}\right) \\
& \quad-\omega^{2} m_{o}\left(\sum_{j=1}^{n} \hat{F}_{j}(\omega) \bar{I}_{j}\right) \\
&\left.+m_{o}\left(-\omega^{2} I_{t}+\mu a^{3} K_{m m}\right) \prod_{k=1}^{n}\left(-\omega^{2}+\omega_{k}^{2}+i 2 \eta_{k} \omega \omega_{k}\right)\right] .
\end{aligned}
$$

III. The modal quantities.

$$
\begin{gathered}
M_{j}=\frac{\left(\sum_{i=1}^{n} m_{i} X_{i j}\right)^{2}}{\sum_{i=1}^{n} m_{i} X_{i j}{ }^{2}}, I_{j}=\frac{\left(\sum_{i=1}^{n} m_{i} h_{i} X_{i j}\right)^{2}}{\sum_{i=1}^{n} m_{i} X_{i j}{ }^{2}} \\
Z_{j}=M_{j} H_{j}=\frac{\left(\sum_{i=1}^{n} m_{i} X_{i j}\right)\left(\sum_{i=1}^{n} m_{i} h_{i} X_{i j}\right)}{\sum_{i=1}^{n} m_{i} X_{i j}{ }^{2}} .
\end{gathered}
$$

The functions $\hat{F}_{j}(\omega)$ and $\hat{F}_{j k}(\omega)$ are

$$
\begin{gathered}
\hat{F}_{j}(\omega)=\left(\omega_{j}^{2}+i 2 \eta_{j} \omega_{j} \omega\right) \prod_{\substack{k=1 \\
k \neq j}}^{n}\left(\omega_{k}^{2}-\omega^{2}+i 2 \eta_{k} \omega_{k} \omega\right) \\
\hat{F}_{j k}(\omega)=\left(\omega_{j}{ }^{2}+i 2 \eta_{j} \omega_{j} \omega\right)\left(\omega_{k}{ }^{2}+i 2 \eta_{k} \omega_{k} \omega\right) \prod_{\substack{l=1 \\
l \neq k, l \neq j}}^{n}\left(\omega_{l}{ }^{2}-\omega^{2}+i 2 \eta_{l} \omega_{l} \omega\right) .
\end{gathered}
$$

